\title{
UN ARANCEL COMERCIAL EN ALICANTE Y ELCHE DURANTE LA BAJA EDAD MEDIA: EL DERECHO DE ADUANA
}

\author{
José Hinojosa Montalvo \\ Universidad de Alicante
}

\section{SUMARIO}

1. El derecho de aduana en Alicante.- 2. El derecho de aduana en Elche.

Las comarcas del mediodía alicantino, al sur de la línea que va desde Biar a Villajoyosa, pasando por Jijona, se incorporaron a la Cristiandad en el siglo XIII, tras el pacto de Alcaraz (1243) entre el monarca murciano Ibn Hud y el infante castellano don Alfonso. Jurídicamente el reino de Murcia, del que formaban parte Alicante y Elche, quedaban bajo la órbita política de Castilla, si bien la ocupación no fue en todos los casos pacífica y algunas poblaciones, como Alicante, hubieron de ser ocupadas por las armas. Este periodo de 1238/43-1296 fue también el de la lenta repoblación del territorio por los cristianos, que va sustituyendo al simple dominio militar, mientras que la campaña militar de Jaime II en 1296 supuso la conquista del reino de Murcia para la Corona de Aragón, iniciando un proceso que terminó con la sentencia arbitral de Torrellas (1304) y el acuerdo de Elche (1305), por los que las tierras del Alicante meridional quedaron incluidas de forma definitiva en el reino de Valencia ${ }^{1}$.

1 La bibliografía sobre estos temas es muy extensa, por lo que sólo me refiero a algunos títulos, todos ellos con amplios apéndices bibliográficos. J.M. DEL ESTAL, Conquista y anexión de las tierras de Alicante, Elche, Oribuela y Guardamar al reino de Valencia por Jaime II de Aragón (1296-1308), Alicante, 1982; "Historia política», en Historia de la provincia de Alicante, III, Murcia, 1985, pp. 171-200; J. TORRES FONTES, Incorporación del reino de Murcia a la Corona de Castilla, Murcia, 1974; J. TORRes FonTes y A. L. Mounn, "Murcia castellana», en Historia de la región murciana, III, Murcia, 1980, pp. 295-387; M. T. FERRER I MALLOL, Notes sobre la conquesta del regne de Múrcia per Jaume II (1296-1304), "Homenatge a la Memòria del Prof. Dr. Emilio Sáez. Aplec d'Estudis dels seus deixebles i col-laboradors», Barcelona, 1989, pp. 27-44. 
Lo que interesa destacar es la política de franquezas y privilegios dictada por Alfonso el Sabio para mantener y fomentar la actividad económica de las localidades incorporadas, haciendo especial hincapié en Alicante por ser, junto con Cartagena, la salida marítima del reino de Murcia, y punto de exportación de los productos murcianos y castellanos ${ }^{2}$. El puerto alicantino se beneficio de una extensa gama de privilegios, desde la exención del pago del ancoraje a los patrones y armadores de la villa (1257), a la concesión en exclusiva del embarque a ultramar, pasando por la limitación del derecho del almojarifazgo a pagar por los mercaderes al 8 por 100 (1257).

Este gravamen del almojarifazgo, que es el que luego pasará en Elche y Alicante a identificarse como dret de duana, puede considerarse como "un conjunto de rentas y derechos, un término que cubre realidades bastante heterogénas y complejas", en opinión de Ladero Quesada, y estaría integrado en el último tercio del siglo XIII por diversos elementos: renta o censo de inmuebles de propiedad real destinados a actividades mercantiles y artesanas; censo sobre tiendas de particulares; derechos de inspección sobre el trabajo artesano y mercantil; uso de pesos y medidas del rey; derechos sobre la organización del mercado y compraventa de determinados productos; fincas próximas a la ciudad; el diezmo de algunos productos; la renta de las tafurerías; el quinto de las cabalgadas; los pechos de judíos y mudéjares, entre ellos el alquilate (quirat) de los mudéjares por todo lo que compran y venden; algunos portazgos y pontazgos; rentas de las salinas, caza y pesca, derecho de feria, montazgos y algún otro menor ${ }^{3}$. También, como señala el mencionado autor, los principales almojarifazgos incorporaban auténticas aduanas, lo que explica el cambio de nombre que se produjo con el paso del tiempo. El 1 de mayo de 1271 Alfonso X declaraba francos a los vecinos de Alicante del pago del portazgo, diezmos y almojarifazgo. Los mercaderes forasteros que vinieran a Alicante pagarían cuatro maravedíes por cien como almojarifazgo de lo que traigan a vender por mar o por tierra, no pagando derechos por las que saquen ${ }^{4}$. Los derechos arancelarios para Alicante se promulgaron el 20 de noviembre de 1258 y fueron ratificados en marzo de 1275.

Tras la conquista del reino de Murcia y la incoporación de estas tierras alicantinas a la Corona de Aragón se mantuvieron todos los privilegios y franquicias de la época castellana, a los que se añadirían los concedidos por

2 J. M. Del Estal, Mª L. Cabanes, F. Gimeno, El libro de los primitivos privilegios de Alicante de Alfonso X el Sabio, Madrid, 1984.

${ }^{3}$ M.A. Ladero Quesada, Fiscalidad y poder real en Castilla (1252-1369), Madrid, 1993. pp. 140-143. En este completísimo trabajo puede verse todo cuanto hace referencia al almojarifazgo en el reino de Murcia en el siglo XIII.

${ }^{4}$ J.M. DEl Estal y otros, El libro de privilegios, n. 12, pp. 31-32. 
los monarcas aragoneses en busca de la fidelidad de sus nuevos súbditos. En el caso del almojarifazgo habría una sustitución de nombres y a finales de la Edad Media sólo Orihuela conservaba tal denominación, mientras que en Elche, Alicante y otras localidades pasaba a ser definido como dret de duana. La confusión de denominaciones a principios del siglo XIV fue frecuente, como ha subrayado $\mathrm{M}^{\mathrm{a}}$. T. Ferrer, usándose aduana y almojarifazgo para designar la misma cosa, mientras que el abonado por las transacciones de los mudéjares se conoce como dret del quirat, cuyo estudio aquí excluimoss. Veamos qué trayectoria siguió el derecho de aduana en las villas de Alicante y Elche en los siglos XIV y XV.

\section{El Derecho de aduana en Alicante}

Las noticias concretas más antiguas sobre el arrendamiento del derecho de aduana, el equivalente al almojarifazgo de otros lugares, percibido en el puerto de Alicante son de 1315 , en que ascendieron a 3.500 suelodos, que en 1316 sufrieron un alza espectacular y fue arrendada por Guillem de Montserrat por 6.000 sueldos, aunque en 1317 recuperaron los niveles habituales, siendo 3.660 sueldos los abonados por su arrendador Esteve de Rubí.

Parece que en los años siguientes los ingresos de la aduana sufrieron un retroceso debido a las prohibiciones reales para comerciar con determinados productos o paises, como en 1321 en que se rebajaron a Guillem Merita 500 sueldos del citado arriendo, mientras que en 1324 de los 2.860 sueldos del arriendo la Corona sólo percibió 1.456 sueldos, 4 dineros, debido a las franquicias comerciales concedidas a los vecinos de Gerona, Barcelona y Palma. El hundimiento del impuesto por el tráfico de mercancías en el puerto alicantino fue casi total a raíz de la guerra de los dos Pedros y las dificultades generalizadas a mediados de la centuria y años posteriores, que tantos estragos causó en la localidad ${ }^{7}$, y en cuatro meses y medio de 1366

$5 \mathrm{M}^{2}$. T. FerRer I MALlOL, Les aljames sarraïnes, p. 145-153, analiza detalladamente el impuesto del quirat abonado por los mudéjares de Elche, Crevillente y Alicante durante el siglo XIV. La falta de espacio nos impide igualmente seguir la evolución del almojarifazgo de Orihuela.

${ }^{6}$ Colección de documentos inéditos del Archivo General de la Corona de Aragón, publicado por Próspero de Bofarull y Mascaro, Barcelona, 49 vols. 1847-1977. XXXIX, p. 112. ACA, Maestre Racional, reg. 1702, fol. 5 r, 17 v, 28 r. Recoge todos estos datos M$^{2}$. T. Ferrer 1 MAllol, Les aljames sarraines de la Governació d'Oriola en el segle X'IV, Barcelona, 1988, pp. 148-149. 1991.

7 J.V. Cabezuelo Pliego, La guerra de los dos Pedros en tierras alicantinas, Alicante, 
tan sólo se recaudaron 100 sueldos, siendo arrendado el derecho en 1367 por la suma de 635 sueldos.

En 1376 se mantiene la atonía mercantil en el puerto y la villa, y ello se refleja en el impuesto, que no encuentra arrendador, por lo que fue recaudado por Bernat Escarabot, vecino de la villa, que sólo obtuvo 343 sueldos, 10 dineros. Pero en los años siguientes hay una ligera recuperación, visible en los 400 y 450 sueldos por los que Pere Guillem arrendó la aduana en 1377 y 1378, descendiendo a 365 sueldos en 1379 . Si en 1380 hubo una subida a 500 sueldos, en cambio en 1381 la caida fue total, y tan solo se ofrecian 140 sueldos por la aduana alicantina, cantidad que fue superada mediante la recaudación directa por Nicolau de Mena, llegándo hasta los 279 sueldos y 2 dineros. Esta década de los ochenta fue de bajos rendimientos impositivos para la aduana, que venía a recaudar por término medio 250 sueldos, e incluso hubo años, 1384 y 1387 , en que tampoco pudo ser arrendada y se recurrió a la recaudación directa, o en 1386 en que tan sólo se recaudaron 92 sueldos y 2 dineros. En estos años el arrendador más notable fue Joan de Taraçona, 1387, 1388 y 1389, que en 1390 ofrece 510 sueldos por este impuesto, alcanzándose por primera vez dicha suma desde hacía muchos años, lo que puede interpretarse como una reactivación económica de la villa, al calor de los privilegios concedidos por los monarcas aragoneses.

Aunque en 1391 se baja otra vez a 400 sueldos, durante la década final del siglo XIV los datos conservados revelan una estabilidad entre los 510 sueldos de 1396 y los 550 de 1397 y 1398. Entre los arrendadores la novedad es la presencia en 1391 del judío alicantino Samuel Rondí, pero en julio de este año la comunidad hebrea de la villa fue asaltada y desarticulada. Los restantes arrendadores, Bertomeu Portes, Joanet Colom, Joan de Mena y Bernat Perpinyà, son todos vecinos de Alicante y ninguno de ellos participó más de un año en el arriendo. Ignoramos sus profesiones y también su estado social o nivel de fortuna ${ }^{8}$.

Hasta 1412 no volvemos a tener datos del derecho de aduana en Alicante, que tan sólo recauda para el fisco real 200 sueldos, siendo arrendado por el vecino de la villa Pere de Fontes, cantidad que sube a 629 sueldos en 1417 cuando lo arrienda Alvaro Franc y a 740 sueldos en 1418, para sobrepasarse por primera vez desde hacía más de cincuenta años la barrera de los 1.000 sueldos en 1419, en que Jaume d'Artés lo arrienda por 1.240 sueldos.

En 1420 y 1421 hay un descenso a 850 y 710 sueldos respectivamente, siendo sus arrendadores Pascual Eximeno y Alí, alfaquí moro de Alicante,

${ }^{8}$ ARV, Maestre Racional, 4543, 4544 y 4545; Ma. T. FERRER, Les aljames sarraines, p. 149. 
el único mudéjar que se documenta arrendando este impuesto". Del resto de la década los únicos datos son de 1422 y 1423 , en que se arrendó por 1.101 y 910 sueldos a Jaume Bernard y Dalmau Porta y Joan Pedrola, que debieron asociarse con este objetivo.

La década de los años treinta ofrece una recaudación fluctuante, entre los 726 sueldos de 1433 y los 900 de 1440 , con sus cotas máximas en 1437 y 1438 , en que se arrienda por 1.103 y 1.000 sueldos respectivamente. En cambio, en los años cuarenta hubo un espectacular incremento del valor de este impuesto, que en 1441 se arrendó por 1.631 sueldos, no bajando de los 1.210 sueldos en $1446^{10}$. El arrendador más destacado fue Joan Pedrolo, que recaudó el impuesto entre 1438 y 1441 .

El derecho de aduana muestra de cuando en cuando acusadas oscilaciones en su trayectoria recaudatoria, que estarían vinculadas al desarrollo del comercio local, y que en el momento presente no estamos en condiciones de reconstruir dado el escaso conocimiento que tenemos de las fuentes de la época. Así, vemos que en 1451 se encargó a Salvador Castelló, corredor, subastar en la plaza de la villa el derecho de aduana, pero nadie ofreció una cantidad superior a las 30 libras, que las autoridades consideraron exigua, por lo que se encargó a Bernat Roig su recaudación, consiguiendo la suma de 1.005 sueldos y 7 dineros, superior, por tanto, a la que se hubiera obtenido de haberse arrendado el impuesto.

Los años cincuenta, a partir de 1453, debieron ser una etapa próspera para Alicante, por cuanto el derecho de aduana pasa de los 1.101 sueldos (1453) a 2.600 (1458), si bien en 1459 hay un notable bajón hasta los 1.435 sueldos. Desde 1460 hay un importante cambio en el arriendo del impuesto, que va a ser gestionado a largo, plazo, durante un periodo de varios años, comenzando por los propios jurados de Alicante, que se lo quedan entre los años 1460 y 1465 por un precio anual de 1.321 sueldos y 6 dineros, lo que proporciona un ingreso seguro y estable a la corona, a la vez que unas posibilidades de ganancias -o de pérdidas, claro está- a la hacienda municipal. El punto de partida a este arriendo concejil fue la concesión hecha por Juan II en un privilegio dado a favor de los jurados alicantinos en 1459. Para estas fechas la economía alicantina comienza a tener un futuro despejado, basado en la especialización agraria (vino, frutos secos, plantas textiles, etc.) y su exportación e integración en los circuitos mercantiles internacionales ${ }^{11}$, por lo que los jurados pueden arriesgar esta inversión.

Sin embargo, al finalizar el plazo estipulado, el consistorio alicantino, a

9 ARV, Maestre Racional, 4549.

10 ARV, Maestre Racional, 4555.

11 José Hinojosa Montalvo, El puerto de Alicante durante la Baja Edad Media, "Anales de la Universidad de Alicante. Historia Medieval», 4-5 (1986), pp. 151-166. 
través de su mensajero Antoni Mingot, intentó que la Corona volviera a conceder el arriendo del impuesto, pero esta vez por un periodo de diez años, señal de que las cosas les fueron bien. Pero el monarca, que veía en esta forma de arriendo una disminución de sus ingresos a largo plazo, se negó a ello y dispuso que Jaume Roca, baile general de Orihuela, procediera al arriendo público, según era costumbre, si bien dejaba abierta la posibilidad de que el Consell de Alicante se lo quedara, siempre que fuera el mejor postor ${ }^{12}$. Y eso es lo que hicieron en 1466, quedándose el arriendo en nombre de la universidad de Alicante por 1.350 sueldos.

También la buena marcha del comercio y, por tanto, de la recaudación impositiva, atrajo las inversiones de los hombres de negocios locales, y así vemos a uno de los más destacados, Antoni Quexans, arrendar el impuesto en 1459 y entre 1467 y 1470, 1472 y 1486. La recaudación sigue ascendiendo en los años sesenta y setenta de la centuria, con un máximo de 2.280 sueldos en 1469 y un mínimo de 1.620 en $1473^{13}$.

En 1474 Juan II vuelve a interesarse personalmente por el derecho de aduana en Alicante tratando de darle un nuevo impulso, ya que según se dice estaba muy descuidado y se producían muchos fraudes -cuyo monto desconocemos-, por lo que encarga al baile general de Orihuela y a las restantes autoridades reales que pongan todo su interés en la percepción de esta exacción, evitando los mencionados fraudes y apoyando en todo a los arrendadores. El objetivo, es obvio, era aumentar los ingresos de las rentas reales ${ }^{14}$. Y así, se reanuda el arriendo a largo plazo, esta vez diez años, a manos de Gisbert de Tolosa, por 1.653 sueldos, 9 dineros cada año. Sin embargo Tolosa no pudo ejercer mucho tiempo como arrendador del derecho de aduana, pues el 5 de febrero de 1478 el monarca, dispuesto una vez más a favorecer al destacado noble mossén Fernando de Rebolledo, revocó el nombramiento hecho a Tolosa y se lo concedió a Rebolledo por diez $a_{n}{ }^{15}$. La concesión previa del rey a Rebolledo databa del 28 de febrero de 1477 y autorizaba al citado noble a arrendar el derecho de aduana cuantas veces quisiera por 50 libras anuales, que era la cantidad media que se venía obteniendo del mismo. La excusa legal fue que Rebolledo ofrecía 1.700 sueldos anuales, pero lo cierto es que, tras los descuentos, la tesorería real tan sólo ingresaba los 1.000 sueldos anuales especificados en la concesión regia, con lo que el principal beneficiado fue Rebolledo.

El plazo de una década concedido al noble de origen aragonés no llegó a completarse, por cuanto el 29 de mayo de 1480 una nueva misiva de Fer-

12 ARV, Real, 403, fol. 140 v-141 r. 12-12-1465.

13 ARV, Maestre Racional, 4564.

14 ARV, Real, 296, fol. 7 v-8 r.

is ARV, Real, 304, fol. 66 v-67 r. 
nando el Católico daba por cancelado el anterior contrato con Rebolledo y se ordenaba su arriendo en pública subasta. Parece que este finiquito hay que buscarlo en el impago por el citado noble de las cantidades adeudadas al fisco real en virtud del mencionado arriendo, ya que el rey dispuso también que las 70 libras debidas por la noble Violante de Rebolledo, procuradora de su hijo Fernando, fueran recuperadas mediante embargo y ejecución de sus bienes ${ }^{16}$. La situación financiera de más de un noble valenciano, sea Rebolledo o el conde de Cocentaina, por citar un par de ejemplos, podía calificarse de precaria e incluso de ruinosa.

En 1484 vemos arrendar el derecho de aduana en la lonja de la villa a Miquel Salort, de Alicante, siéndolo en años sucesivos a otros particulares, entre ellos el portugués Diego Lopes en 1488 por 3.001 sueldos. La tendencia alcista del arrendamiento aparece imparable a finales del siglo Xv, en que se superan ya los 3.000 sueldos en 1485 , prosiguiendo esta tónica en años siguientes, con alguna que otra oscilación, como los 2.600 sueldos de 1490, o la ausencia de arrendador voluntario en 1491, encargándose su recaudación a Pere del Feo, que consigue 3.269 sueldos y 4 dineros ${ }^{17}$. Quizá los márgenes de beneficios fueran muy estrechos y los posibles arrendadores no consideraran conveniente arriesgar sus capitales por tan poco.

Haciendo un balance global del impuesto vemos como nunca se llegó a alcanzar la elevada suma de los 6.000 sueldos de 1316, aunque al faltarnos datos anteriores no sabemos si esta cifra puede calificarse de «normal» o más bien, a deducir por la trayectoria posterior, de anormal. Desde luego, hubo de pasar mucho tiempo, hasta finales del siglo Xv, para recuperar el nivel de los 3.000 sueldos, resultado todo ello de la difícil coyuntura económica por la que atravesó Alicante al menos desde mediados del siglo XIV, sobre todo por la guerra con Castilla, y la lenta recuperación de su comercio. A pesar de todo, el paso de los 343 sueldos de 1376 a los 3.269 de 1491 habla a las claras de la importancia que el derecho de aduana llegó a alcanzar en las rentas de la bailía de Alicante, hasta convertirse en la principal de las fuentes de ingresos en los albores de la Modernidad.

La relación detallada de los que arrendaron el derecho de aduana en Alicante es la siguiente:

1316. Guillem Montserrat. 6.000 s.

1317. Esteve de Rubí. 3.660 s.

1321. Guillem Merita, de Alicante.

1324. $1.456 \mathrm{~s}, 4 \mathrm{dr}$.

1366. $100 \mathrm{~s}$ (4 meses)

1367: $635 \mathrm{~s}$.

16 ARV, Real, 304, fol. 70 r-71 r.

17 ARV, Maestre Racional, 4573. 
1376: Bernat Escarabot. $343 \mathrm{~s}, 10 \mathrm{dr}$.

1377: Pere Guillem, de Alicante. 400) s.

1378: Pere Guillem. 450 s.

1387: Tomás de Maçanet. 160 s, $6 \mathrm{~d}$.

1388: Joan de Taraçona. 320 s.

1389: Joan de Taraçona. $340 \mathrm{~s}$.

1390: Joan de Taraçona. 510 s.

1391: Samuel Rondí, judio de Alicante. $400 \mathrm{~s}$.

1396: Bertomeu Portes, vecino de Alicante. 510 s.

1397: Joan de Mena y Joanot Colom, vecinos de Alicante. 550 s.

1398: Bernat Perpenyà. $550 \mathrm{~s}$.

1412: Pere de Fontes, vecino de Alicante. $200 \mathrm{~s}$.

1417: Alvaro Franch. 629 s.

1418: Jaume d'Artés, de Alicante. $740 \mathrm{~s}$.

1419: Jaume d'Artés, de Alicante. $1.240 \mathrm{~s}$.

1420: Pascual Eximeno. 850 s.

1421: Alí alfaquí, de Alicante. $710 \mathrm{~s}$.

1422: Jaume Bernard. $1.101 \mathrm{~s}$.

1423: Dalmau Porta y Joan Pedrola, de Alicante. $910 \mathrm{~s}$.

1433: Alfonso de Sevilla. 726 s.

1434: Joan de Mena. 870 s.

1435: Alfonso de Sevilla. 731 s, 6 d.

1437: Alfonso Dexe. $1.103 \mathrm{~s}$.

1438: Joan Pedrolo. $1.100 \mathrm{~s}$.

1439: Joan Pedrolo. 466 s, 8 dr.

1440: Joan Pedrolo. $900 \mathrm{~s}$.

1441: Joan Pedrolo. 1.631 s.

1442: Francesc d'Artés. $1.452 \mathrm{~s}$.

1443: Francesc d'Artés. $1.540 \mathrm{~s}$.

1444: Bernat Roig. $1.400 \mathrm{~s}$.

1445: Jaume Busaldo. $1.260 \mathrm{~s}$.

1446: Bertomeu Beltrà. $1.210 \mathrm{~s}$.

1451: Bernat Roig, menor. 1.005 s, $7 \mathrm{~d}$.

1452: Diego Mendoza. 800 s.

1453: Alfonso Bongosar. $1.101 \mathrm{s.}$

1454: Manuel Porles. $1.130 \mathrm{~s}$.

1455: Pere Pascual. 1.460 s.

1456: Alfonso Bongosar. $1.600 \mathrm{~s}$.

1457: Alfonso Bongosar. $1.750 \mathrm{~s}$.

1458: Alfonso Pastor. $2.600 \mathrm{~s}$.

1459: Antoni Quexans. $1.435 \mathrm{~s}$.

1460-1465: Los jurados de la villa. $1.321 \mathrm{~s}, 6 \mathrm{dr}$. año.

1466: Antoni Mingot, en nombre del Consell. $1.350 \mathrm{~s}$. 
1467: Antoni Quexans. 1.500 s.

1468: Antoni Quexans. 1.640s.

1469: Antoni Quexans. 2.280 s.

1470: Antoni Quexans. 1.665 s.

1471: Miquel Salort, de Alicante. 2.393 s.

1472: Antoni Quexans. 1.721 s.

1473: Joan Lopiz, de Alicante. $1.620 \mathrm{~s}$.

1474-77: Gisbert de Tolosa, a 10 años, a 1.653 s, 9 dr. año.

1478: Mossén Ferran de Rebolledo, a 10 años, a 1.000 s.

1484: Miquel Salort, de Alicante.

1485: Bertomeu de Seva, de Alicante. $3.280 \mathrm{~s}$.

1486: Antoni Quexans, mercader de Alicante. $3.000 \mathrm{~s}$.

1487: Martínez de Vera, lugarteniente del baile general. $3.0001 \mathrm{~s}$.

1488: Diego Lopes, portugués. 3.001 s. 1489: Diego Lopes, $3.001 \mathrm{~s}$.

1490: Bernat Calatrava, $2.600 \mathrm{~s}$.

1491: Pere Delfeo, de Alicante. 3.269 s, 4 dr.

En cuanto al origen de los arrendadores del impuesto, aunque normalmente no se indica, hay que pensar que casi todos son oriundos de Alicante, con la excepción del portugués Diego Lopez en 1488 y 1489, testimonio así mismo de la instalación de operadores mercantiles extranjeros en la villa, de los que hay testimonios desde mediados de la centuria.

Las minorías religiosas, muy débiles demográficamente en Alicante, están representadas por un mudéjar alicantino en 1421, mientras que la participación judía no pasa tampoco de ser testimonial, con Samuel Rondi como arrendador en 1391 y un tal Isac Baccar, citado como judío residente de Alicante, en 1426 y que tiene el arriendo del derecho de aduana ese año, aunque no sabemos por cuánto dinero se lo quedó, pues no se conservan las cuentas del Maestre Racional de ese año. Recordemos que en 1391 la judería de Alicante fue asaltada y sus judíos convertidos al cristianismo o dispersos, por lo que la mención de este judío es la primera que hemos detectado desde aquella fecha ${ }^{18}$. En 1426 Isac mantenía un pleito con Daniel Mascarós, mercader de Valencia, cuyo factor y procurador en Alicante, Francesc d'Artés, se había quejado al rey porque el judío había cobrado 49 florines a Mascarós, quien alegaba poseer franquicias. El 26 de agosto de 1427 Alfonso el Magnánimo dictó sentencia a favor de Mascarós, obligando al judío a devolverle dicha suma, pero Isac se defendió alegando que estaba en poder del baile de Alicante ${ }^{19}$.

18 J. Hinojosa Montalvo, Bosquejo bistórico de los judíos en tierras alicantinas durante la Baja Edad Media, "Actes del Ir. Col.loqui d'Història dels jueus a la Corona d'Aragó", Lleida, 1991, pp. 207-220.

19 ARV, Real, 36, fol. 4 r-5 r. 13-3-1426; Real, 461, fol. 11 v-12 r. 6-6-1427; Real, 39 , fol. 93 r. 26-8-1427. 
Predomina el arrendamiento de forma individual, aunque en ocasiones se forman sociedades integradas por dos individuos y por un periodo de tiempo anual (Joan de Mena y Joanet Colom en 1397, o Dalmau Porta y Joan Pedrola en 1423, por ejemplo), repartiéndose los beneficios entre las partes. Lo habitual es que un individuo arriende el derecho por un año, siendo pocos los que vuelven a reaparecer en años sucesivos, como puede verse en la tabla adjunta: Pere Guillem (1377-78), Joan de Taraçona (138890), Jaume d'Artés (1418-19), Joan Pedrolo (1438-41), etc.

Aun cuando no se indican, por lo general, sus profesiones, de algunos de ellos sabemos, o podemos sospechar, que eran mercaderes, como Jaume d'Artés (1418-19) o Francesc d'Artés (1441, 1443), pues un Pere d'Artés, mienbro de esta familia, está muy vinculado a las actividades comerciales de la villa. También los Mingot y los Quexans forman parte del grupo destacado de los mercaderes alicantinos a fines del Medievo. Socialmente se incluyen en el grupo de la oligarquía político-económica local, que participa de forma destacada en el gobierno municipal (Antoni Mingot es jurado en 1466) e incluso como representantes de la Corona, como Martínez de Vera, baile local y destacado miembro de la nobleza local, que en 1487 arrienda el impuesto, pero que tampoco desdeña traficar con esclavos u otras mercancías

La recaudación del derecho de aduana en Alicante no parece haber sido motivo de muchas tensiones o problemas entre los recaudadores o municipios. Ya vimos los que tuvo el judío Isaac en 1426, o el pleito que en 1458 mantuvieron Jaume Avellà, vecino de Penáguila, con Alfonso Bongosa, arrendador del impuesto, quien habría realizado unas supuestas confiscaciones ilegales contra Avellà. Don Juan, hermano del monarca y lugarteniente general en el reino de Valencia, comisionó a Jaume Gil, baile de Alicante, para que resolviera el contencioso, con la ayuda de Pere de Mora, doctor en derecho de Xàtiva ${ }^{20}$.

Tampoco faltó algún que otro pleito con localidades vecinas, como con Elche en 1389 cuando Guillem Salort, síndico y mensajero de Alicante se quejó ante el rey porque los ilicitanos les obligaban a pagar el derecho de aduana, siendo así que los vecinos de Alicante por antiguos privilegios estaban exentos del pago. Juan I ordenó al gobernador general de Orihuela que, tras oir a las partes, resolviera dicha reclamación según correspondiera en justicia $^{21}$. No parece que la sentencia del gobernador -que desconocemoscontribuyera a solucionar las divergencias, por cuanto en 1393 hay una nueva queja al rey porque el baile de Elche obligaba a los vecinos de Alicante a pagar indebidamente el derecho de aduana, lo que iba contra fueros,

20 ARV, Real, 88, fol. 48 v-49 r. 10-10-1458, Zaragoza.

${ }^{21}$ Archivo Municipal de Alicante, Armario 1, libro 2, fol. 66 v. 18-2-1389, Monzón. 
a razón de 20 dineros por cada 100 sueldos. Los colectores de Elche y Crevillente les cobraban el impuesto cuando los alicantinos venían de moler el grano en los molinos de estas localidades, a razón de dos sueldos por cahiz, motivando una queja de Alicante al monarca, por lo que Juan I dispuso que el baile de Elche o sus procuradores acudieran a la corte a explicar su conducta $^{22}$.

Con Valencia hubo también roces, pero en este caso motivados por la duplicidad en el cobro de impuestos en 1474. En virtud de diversos privilegios concedidos a Alicante los que acudieran a la feria de octubre estaban exentos en sus contratos, compras, etc. del pago del peaje y del derecho de la aduana, además de otros derechos reales, pero tales exenciones no fueron respetadas en Valencia, donde se exigían ciertos derechos a las ropas que se habían comprado o vendido en Alicante, lo que motivó la queja de las autoridades alicantinas al monarca, quien ordenó al baile general del reino que se respetaran los privilegios de Alicante y no se cobraran aquellas exacciones $^{23}$.

Los fondos recaudados con el derecho de aduana en Alicante fueron utilizados en 1480 de forma excepcional para pagar el salario anual de 50 libras del alcaide del castillo de Callosa de Segura, Jaume Pérez, ya que era la única forma posible de que éste cobrara su sueldo.

\section{El DeREChO de aduana en ElChe}

También en Elche a finales de la Edad Media el término almojarifazgo ha dejado de estar en uso y se utiliza siempre el de aduana, aunque el primero todavía se empleaba en 1315 , en que se definía como el dret que $\bullet /$ mercaders christians paguen de les mercaderies que compren e venen ${ }^{24}$. Para los mudéjares se utiliza, como dijimos,el vocablo quirat.

Es difícil seguir la trayectoria del impuesto del amojarifazgo o aduana en Elche, ya que con frecuencia aparece en los cuadernos de rentas englobado con otras exacciones. En las rentas reales de 1315 ascendió a 1.500 sueldos, mientras que el derecho del puerto del Cap de l'Aljub era de 2.000

22 ACA, Real Cancillería, reg. 1853, fol. 135 v-136 r. 24-1-193, Valencia. De la queja de los alicantinos se deduce la inexistencia de molinos harineros en Alicante y su término, 0 bien que en aquél año los caudales de agua fueron insuficientes para que funcionaran los molinos de Alicante.

${ }^{23}$ ARV, Real, 111, fol. 5 v-6 r. 28-9-1474, Rosas.

${ }^{24} \mathrm{M}^{2}$. T. Ferrer I MAllol, Les aljames sarraïnes, p. 146. Al igual que para Alicante seguimos los datos que proporciona la autora para buena parte del siglo XIV, completándolos con fuentes procedentes del Archivo Municipal de Elche. 
sueldos, cantidades que no se corresponden con las que figuran en las cuentas del baile general Joan Rolf de 1316-1317, que suman 1.110 sueldos, 3 dineros y malla para el primero y 737 sueldos y malla para el primero en los ocho últimos meses de 1316. En 1317 el almojarifazgo proporciona unos ingresos de 1.656 sueldos. Esta cantidad final percibida por la bailía de Orihuela-Alicante es una vez descontados los salarios de los colectores.

En 1324, al igual que sucedió en Alicante, las exenciones reales concedidas a barceloneses y mallorquines produjeron un descenso en la recaudación de las rentas de Elche y, como señala a $\mathbf{M}^{2}$. T. Ferrer, todo hace pensar unos intensos lazos comerciales entre Mallorca y Elche, por cuanto Jaime II insiste en una carta del 11 de agosto de 1323 al baile general de Orihuela en que respete a los mallorquines la franquicia del almojarifazgo en Elche, Elda y Novelda ${ }^{25}$.

Hay pocos datos para el resto de la centuria sobre el arriendo del derecho de aduana en Elche, ya que la villa pasó a integrarse en el señorío y no se conservan los cuadernos de cuentas. En 1358, cuando muere el infante Juan, señor de Elche, la aduana la tenía arrendada Guillem de Maçanet.

También los judíos de la localidad participaron como arrendadores del impuesto y en 1360 se le concedió el arriendo a Abrahim Abenbahe por 1.100 sueldos, pero la reina Leonor lo rechazó, ya que otro correligionario, Jucef Abentaurell ofrecía 1.500 sueldos. Sin embargo, se le dió a Abenbahe la posibilidad de quedárselo por el mismo precio que ofrecía Abentaurell, quien resultó ganador de la pugna, quedándose el arriendo por un plazo de dos años asociado con un cristiano, Pere Fernández de Mesa, perteneciente a una destacada familia local, por 1.700 sueldos el primer año y 2.000 el segundo ${ }^{26}$.

Parece que en Elche los judíos mostraron cierta predisposición en sus actividades financieras al arriendo de impuestos, entre ellos el de la aduana, algo nada inusual entre esta minoría. Así se deduce de una queja presentada por las autoridades locales en 1378 al monarca, solicitando que para evitar abusos los judíos no pudieran participar en el arriendo de los impuestos locales. Pedro el Ceremonioso accede a la demanda de los jurados ilicitanos, si bien excluye a los judíos del derecho de aduana, que podrían seguir arrendando.

El impuesto lo abonaban los mercaderes que entraban y salían de las localidades, debiendo presentar una relación con las mercancías que llevaban para que se pudiera comprobar cuáles eran las que traían, las de tránsito o las adquiridas y vendidas, con el fin de abonar el correspondiente derecho. Una serie de vigilantes en las puertas de la localidad y en los caminos

${ }^{25} \mathbf{M}^{2}$. T. Ferrer I MALLOL, Les aljames sarraines, p. 149-151.

${ }^{26} \mathbf{M}^{2}$. T. Ferrer I MALLOL, Les aljames sarraïnes, p. 150. 
trataban de impedir el fraude. En 1324, por ejemplo, se gastaron 1.737 sueldos y 2 dineros en salarios de guardias de los caminos ilicitanos. Lo que no impide el fraude para tratar de no pagar el impuesto, como hizo en 1378 Hamet Çaquitil, del término de Calpe, que entró con su barca entre las puntas de Alicante para esquivar el pago del derecho de aduana ${ }^{27}$.

Los naturales de Alicante o de Elche estaban exentos del pago del derecho de aduana, lo que con frecuencia provocaba tensiones con los arrendadores, dispuestos siempre a cualquier abuso contra el mercader, a lo que las autoridades tuvieron que poner coto. Así en el memorial enviado por los jurados el 26 de marzo de 1382 al infante Martín los mercaderes acusaron a los arrendadores de que ponían dificultades a los forasteros a la hora de la presentación del manifiesto de las mercancías, ya que preferían confiscarlas a aquellos que no cumplían los requisitos exigidos. También se quejaban de que los arrendadores judíos pretendían cobrar el impuesto a los vecinos de Elche, cuando éstos estaban exentos en toda la tierra del rey, por lo que reclaman que se respete dicha franquicia. Igualmente, si los vecinos llevan sus paños a preparar o a terminarlos a Orihuela u otros lugares y no lo notifican a los arrendadores se los confiscaban, como si fueran de moros o de extranjeros, que sí pagaban este derecho.

Otro problema que se planteaba era el del marco físico para la recaudación del impuesto. Según exponían los jurados, antes de la guerra con Castilla, los arrendadores del impuesto tenían una casa llamada «la duana», donde los moros y forasteros manifestaban lo que compraban y vendían al aduanero, allí presente, quien resolvía todos los conflictos que surgieran con relación a la aduana. Después de la guerra, los judíos arrendadores, que $y$ meten molta mala costum, no se preocuparon por la ubicación de la aduana, de modo que los mercaderes que necesitaban un manifiesto tenían dificultades para encontrar a los aduaneros, lo que luego se traducía en confiscaciónes por parte de éstos al no llevar los correspondientes albaranes, lo que originaba una disminución del comercio, ya que muchos forasteros no se atrevían a venir por temor a tales represalias. La propuesta de las autoridades al infante era que la casa de la aduana esté donde se celebra el mercado, con el fin de evitar dichos fraudes y otros, como el cobro de tasas indebidas a los forasteros, ya que al no haber capítulos ni ordenanzas por escrito piden lo que quieren, bajo amenaza de embargo ${ }^{28}$. Tales abusos traían como consecuencia represalias comerciales sobre los vecinos de Elche cuando acudían a otros lugares.

27 ARV, Maestre Racional, 4543, fol. 50 v. M$^{2}$. T. FerRer I MAllol, Les aljames sarraines, p. 151.

28 Archivo Municipal de Elche, Manual de Consells, 1, fol. 238 v-240 r. Existía en Elche una casa llamada la duaneta, donde el 1-11-1379 se reunió el Consell de la villa. 
El 6 de mayo el infante Martín, a la sazón en Valencia, escribe al Consell de Elche haciéndose eco de las quejas arriba citadas y ordenando a los arrendadores que no cobren derecho alguno sino sobre las mercaderías que antiguamente se acostumbraba a cobrar, a la vez que en carta al baile y procurador en Elche dispone que los aduaneros ejerzan su oficio en la casa de la aduana, donde estaba anteriormente ${ }^{29}$. La puesta al día de la normativa legal tuvo que esperar un poco más, y el 28 de octubre de 1383 en la reunión que ese día tuvo el consistorio se expuso un libro de tiempos de don Juan Manuel con los capítulos del amojarifazgo qui ara es duana, acordándose su traslado a pergamino con el fin de tenerlo a mano cuando surgieran problemas legales ${ }^{30}$.

Junto a posibles abusos de los arrendadores, otro de los problemas que se derivaban de la percepción del derecho de aduana y al que tenían que hacer frente las autoridades locales era la pretensión de otras villas y ciudades del reino de cobrar este impuesto a los vecinos de Elche, quienes, como sabemos, estaban exentos de su pago. Así el 27 de noviembre de 1414 los jurados se quejaban a sus colegas de Barcelona, ciudad a la sazón señora de la villa, y pedían protección frente a los abusos de la ciudad de Valencia, que al igual que otras villas del reino, de forma indebida y de acuerdo con los bailes generales o especiales del rey en el reino, no querían observar con los ilicitanos el privilegio de franquicia del derecho de aduana concedido por los reyes de Aragón. Los jurados de Elche piden a los de Barcelona que hablen de ello con el rey, ya que el derecho es una regalía de la señoría y a ellos les corresponde hacerlo ${ }^{31}$. Parece que la petición no debió surtir el efecto esperado por los jurados ilicitanos, por cuanto el 22 de junio de 1417 vuelven a reclamar a los jurados y consejeros de Barcelona que se respete a los vecinos de Elche la franquicia del derecho de aduana.

Un ejemplo de estos abusos lo tenemos en 1427, cuando Joan Ivanyes, de Elche, fue obligado en Alicante a pagar el derecho de aduana por ciertas ropas que había comprado en pública subasta por 80 sueldos. El baile local, Pere Ripoll, no quiso respetarle la franquicia y le obligó a pagar 4 sueldos por el derecho de aduana, cuya devolución reclamaba Ivanyes a las autoridades alicantinas ${ }^{32}$. También años después, en 1443, hubo problemas similares porque el baile de Xàtiva no quería respetar la franquicia de los ilicitanos, lo que llevó a las autoridades concejiles de Elche a instruir un proceso ante el gobernador general de Orihuela por la mencionada transgresión,

29 AME, Manual de Consells, 1, fol. 247 v-248 v.

${ }^{30}$ AME, Manual de Consells, 1, fol. 309 v.

31 AME, Manual de Consells, 3. 27-11-1414.

32. AME, Manual de Consells, 6. 8-1-1427. 
encargándose de la defensa del Consell de Elche el notable abogado valenciano, micer Gabriel de Palomar ${ }^{33}$.

De la evolución seguida por el derecho de aduana en Elche durante los siglos XIV y XV es muy poco lo que sabemos, ya que por el momento sólo han aparecido algunos de los cuadernos de la renta feudal de la señoría de Barcelona. Por ellos sabemos que en 1399 el impuesto lo arrendó Antoni Navarro, vecino de Elche, por 2.520 sueldos, abonando 50 sueldos como derecho del marco. En 1400 el arrendador fue Ferran de Galbe por 2.361 sueldos y 6 dineros, siendo la siguiente noticia de 1411, en que Pere Ferrández se lo quedó por 2.500 sueldos. En 1412 la suma del arriendo ascendió a 2.025 sueldos, pagados por Antoni Quexans, menor, y en 1413 fue el arrendador Lope Sanxes de Llorca por 2.225 sueldos $^{34}$. Para 1417 se había llegado ya a los 3.000 sueldos. En 1399 se cita a un Nicolau Bonmatí como arrendador de la aduana, quien realizó obras y mejoras en el obrador situado en el arrabal de la morería, que cada año se arrendaba con la aduana. Este Bonmatí no corresponde con el Antoni Navarro que nos indican las cuentas de la señoría, por lo que cabe pensar que fuera un arrendador del año anterior $u$ otro, cuyos gastos se incluyen en esas cuentas ${ }^{35}$.

Todos los arrendadores son vecinos de Elche y la trayectoria del impuesto en estos primeros años del siglo $\mathrm{XV}$ se caracteriza por la estabilidad del mismo, entre los 2.000 y los 2.500 sueldos, cantidad importante si la comparamos con Alicante por aquellas fechas, donde apenas si se recaudaban unos centenares de sueldos, sin llegar al millar, lo que parece reflejar una mayor actividad mercantil en Elche.

De mediados de la centuria tenemos algún dato suelto, como el que en 1453 fueron arrendadores Galcerà Olivera y su mujer, a los que el Consell solicitó fiadores por la cantidad que todavía debían al municipio de dicho arriendo $^{36}$, y en 1454 fue arrendador Ferrando Quirant, sin que sepamos el monto del arriendo. En 1465 el arrendador fue Acet Beagip por 4.000 sueldos; en 1466 se lo quedó Guillem d'Alvado por 4.060 sueldos y en 1467 Mahomat Benocia y Çaat Zaem por $4.031^{37}$, mostrando el impuesto una gran estabilidad durante estos años. El derecho de aduana es una importante fuente de ingresos para la señoría, representando en estos años sesenta el

33 AME, Manual de Consells, 12, 15-3-1443.

34 ARV, Maestre Racional, 9717, 9718 y 9719.

35 ARV, Maestre Racional, 9717, fol. 32 r. Los gastos de las obras en dicho obrador fueron de 9 sueldos, 8 dineros. En 1400 hubo también obras en dicho obrador por el arrendador, sumando 22 sueldos, 2 dineros.

${ }^{36}$ AME, Manual de Consells, 15. 9-5-1456. Los fiadores fueron Antoni d'Ancares y Esteve d'Ancano.

37 ARV, Maestre Racional, 9715, fol. 8, 31 v y $41 \mathrm{r}$. 
$12,9 \%$ de la renta feudal, porcentaje nada desdeñable en el conjunto global. Es interesante destacar la presencia de mudéjares de la morería de Elche como arrendadores, lo que indica que hay un grupo de ellos con el suficiente potencial económico para arriesgar parte de su capital en negocios especulativos, a lo que contribuiría la estabilidad económica de la época. La carencia de fuentes para otros años no permite deducir si se trata de un fenómeno aislado de estos años o hubo otros arrendadores mudéjares en años anteriores o posteriores.

Tampoco nos han llegado las tarifas percibidas sobre los diferentes productos y sólo alguna noticia dispersa, como la sentencia dada en 1485 contra el judío Samuel el Naci, interpuesta por el arrendador Antoni Quexans, en la que se indica que el impuesto se aplica a razón de 20 dineros por libra, o sea, un $8,33 \%^{38}$.

Si comparamos las percepciones del impuesto en Alicante y Elche vemos un balance favorable para la villa ilicitana, cuyo derecho de aduana, en los datos conservados, siempre aventajó a Alicante, incluso cuando a fines de la centuria esta ciudad ha superado ya los 3.000 sueldos anuales, lo que testimonia, en definitiva, una actividad comercial en Elche superior a la de Alicante y más intensa de lo que hasta ahora creíamos. Si la comparación la establecemos con Orihuela también es Elche la que sale favorecida en la mayoría de los años, y así, por ejemplo, el almojarifazgo de Orihuela es arrendado en los años 1465, 1466 y 1467 por $2.400,2.220$ y 2.000 sueldos, prácticamente la mitad que en Elche. En 1484, en cambio, Orihuela arrienda el almojarifazgo por 6.000 sueldos, llegándose en 1491 a los 9.150 sueldos, aunque ahora se incluye el nou dret de entrada e exida e coses vedades ${ }^{39}$. De Elche no se conservan datos. La falta de espacio nos impide extendernos en un análisis detallado del amojarifazgo de Orihuela.

Por último, recordemos que el derecho de aduana se recaudaba también en otras localidades alicantinas, como era Monforte, entonces aldea de Alicante, en donde sabemos que en 1490 se recaudaron 40 sueldos y 82 en 1491, aunque desconocemos quiénes fueron los arrendadores. En otros casos la única noticia que nos ha llegado es la confirmación hecha por la corona de la franquicia del mencionado derecho a los vecinos de una localidad, como la ratificación de Martín el Humano el 22 de febrero de 1397 a las villas de Biar y de Jijona del derecho de aduana o almojarifazgo, el montazgo y cualesquiera otros impuestos ${ }^{40}$.

${ }^{38}$ AME, Protocolos notariales, $n^{0} 4,3-23-1485$. La sentencia fue dada por el juez Antoni Ferri, notario y abogado.

39 ARV, Maestre Racional, 4573.

40 ACA, Real Cancillería, reg. 2209, fol. 82 v-83 r. En dicho documento se ratifica la franquicia del derecho del carnaje o borregatge en Alicante y Orihuela. 
También los vecinos de Castalla estaban libres del pago de aduana, pontazgo, pasaje, etc. por privilegios de los reyes de Aragón, confirmados por Juan II el 25 de junio de 1466 al noble Baltasar Lladró, señor de la villa, y extensiva también a los lugares de Tibi y Onil ${ }^{41}$. Nótese que todas estas localidades estaban en la zona fronteriza y una de las tácticas seguidas por la Corona para atraer pobladores fue siempre la concesión de amplias franquicias y libertades. Lo mismo que hizo con Villajoyosa tras la incorporación de la villa al patrimonio real, en que, con el fin de engrandecerla, Juan II el 12 de enero de 1468 declara francos e inmunes a todos sus habitantes y a la universidad de los derechos de peaje o aduana, almudinaje, lezda y otros derechos reales ${ }^{42}$.

\section{RÉSUMÉ}

Pendant les siècles qui composent le Bas Moyen-Age, dans les régions méridionales du royaume de Valence, -royaume qui, pendant la seconde moitié du XIII $^{\text {¿̀me }}$ siècle faisait partie du royaume de Murcie-, les transactions mercantiles étaient grevées de divers impôts parmi lesquels l'almojarifazgo -terme qui fut maintenu à Orihuela- ou droit de douane (à Elche ou Alicante). En ce qui concerne Alicante, on conserve encore des informations du début du XIv'me siècle, selon lesquelles ces recettes d'impôts procuraient des revenus qui dépassaient les 3.500 sous l'an. Les difficultés du milieu du siècle, en particulier la guerre, ont ruiné l'économie locale et les recettes de l'impôt entrèrent dans une phase de léthargie qui dura jusqu'à la moitié du $\mathrm{Xv}^{\text {ème }}$ siècle, époque pendant laquelle commence déjà une période de récupération, en accord avec la relance économique de la ville. Les fermiers sont alicantins, certains d'entre eux marchands, membres de l'oligarchie locale. Le fermage individuel prédomine, bien que parfois des sociétés spécifiques se constituent.

Les données qui concernent Elche datent de 1315 et on voit les juifs de l'endroit participer activement dans l'affermage jusqu'en 1391. Au Xvème siècle apparaissent aussi des fermiers mudéjars. L'impôt se maintient stable au début du $\mathrm{XV}^{\text {ème }}$ siècle, il est de 2.000 à 2.500 sous, bien supérieur aux recettes d'Alicante. Le droit est une importante source de revenus pour la seigneurie -la ville de Barcelone- et répresente $12,9 \%$ de la rente féodale dans les années soixante du $\mathrm{XV}^{\text {ème }}$ siècle.

${ }^{41}$ ARV, Real, 396, fol. 63 v-65 v.

42 ARV, Real, 291, fol. 53 r-54 r. 


\section{SUMMARY}

During the low Middle Ages, in the southern areas of the Reign of Valencia -that during the second half of the XIII ${ }^{\text {th }}$ century belonged to the Reign of Murcia-, the trading transactions were burdened with different taxes, between them customs dues, almojarifazgo as it is still called in Orihuela or dret de duana in Alicante and Elche.

As far as Alicante is concerned, we have texts dating from the beginning of the XIV ${ }^{\text {th }}$ century, where an amount of more than the annual 3.500 pays of incomes were reached. The difficulties by the middle of the century, above all war, ruined local economy and this tax was left aside till the middle of the $\mathrm{XV}^{\text {th }}$ century, when a clear period of recovering starts, parallel to the economic take off of the city. The landlords are native of Alicante, some of them are traders, members of the local oligarchy. There are mostly individual landlords, though they sometimes created specific societies.

In Elche, we find information since 1315, according to which local Jews participated actively in farming out since 1391. During the $\mathrm{XV}^{\text {th }}$ century Mudejars also rented areas. Tax remain stable at the beginning of the $\mathrm{Xv}^{\text {th }}$ century around 2.000 and 2.500 pays, much above what was commonly collected in Alicante. Customs dues bring an important source of income for the landlords -the city of Barcelona-, it represents $12,9 \%$ of feudal incomes during the years sixties of the $\mathrm{XV}^{\text {th }}$ century. 